\title{
Comparison of Paclitaxel-, Sirolimus-, and Zotarolimus-Eluting Stents in Patients With Acute ST-Segment Elevation Myocardial Infarction and Metabolic Syndrome
}

Min Goo Lee, MD; Myung Ho Jeong, MD; Youngkeun Ahn, MD; Jeong Gwan Cho, MD; Jong Chun Park, MD; Jung Chaee Kang, MD; Shung Chull Chae, MD; Seung Ho Hur, MD; Taek Jong Hong, MD; Young Jo Kim, MD; In Whan Seong, MD; Jei Keon Chae, MD; Jay Young Rhew, MD; In Ho Chae, MD; Myeong Chan Cho, MD; Jang Ho Bae, MD; Seung Woon Rha, MD; Chong Jin Kim, MD; Donghoon Choi, MD; Yang Soo Jang, MD; Junghan Yoon, MD; Wook Sung Chung, MD; Ki Bae Seung, MD; Seung Jung Park, MD; other Korea Acute Myocardial Infarction Registry Investigators

\begin{abstract}
Background: The purpose of the present study was to compare the efficacy and safety of paclitaxel-eluting stent (PES), sirolimus-eluting stent (SES), and zotarolimus-eluting stent (ZES) in primary percutaneous coronary intervention (PCI) for acute ST-segment elevation myocardial infarction (STEMI) with metabolic syndrome (MS).

Methods and Results: Using data from Korea Acute Myocardial Infarction Registry (KAMIR; November 2005December 2007), a total of 1,768 MS patients with STEMI who underwent primary PCI were enrolled: The PES group was 634, SES group, 906, and ZES group, 228. The primary endpoint was major adverse cardiac event (allcause death, re-myocardial infarction, target lesion revascularization) during 12 months follow-up. At 12 months, the cumulative incidence of primary endpoint in the PES, SES, and ZES groups was $10.9 \%, 9.1 \%$, and $11.0 \%$, respectively $(\mathrm{P}=0.086)$. Incidence of death, recurrent myocardial infarction, or target lesion revascularization did not differ among the 3 groups. There were 7 episodes of acute $(0.3 \%$ in PES group, $0.4 \%$ in SES group, and $0.4 \%$ in ZES group, respectively, $\mathrm{P}=0.773$ ) and 18 episodes of cumulative stent thrombosis including late stent thrombosis (0.9\% in PES group, $1.0 \%$ in SES group, and $1.3 \%$ in ZES group, respectively, $\mathrm{P}=0.448$ ).
\end{abstract}

Conclusions: Implantation of SES, PES, and ZES in MS patients with STEMI undergoing primary PCI provided comparable clinical outcomes in patients enrolled in KAMIR. (Circ J 2011; 75: 2120-2127)

Key Words: Drug-eluting stent; Metabolic syndrome; Myocardial infarction

$\mathbf{P}$ rimary angioplasty has become the standard of care for acute ST-segment elevation myocardial infarction (STEMI), but its long-term success is limited by the occurrence of re-stenosis. ${ }^{1,2}$ The introduction of drugeluting stents (DES) has greatly alleviated this problem, and their use in percutaneous coronary intervention (PCI) has markedly increased compared with bare metal stents (BMS). ${ }^{3}$ Although superiority over BMS has been demonstrated for a variety of DES, currently available and approved DES might not necessarily be associated with equal performance effi-

Received March 8, 2011; revised manuscript received April 17, 2011; accepted May 10, 2011; released online July 14, 2011 Time for primary review: 29 days

Chonnam National University Hospital, Gwangju (M.G.L., M.H.J., Y.A., J.G.C., J.C.P., J.C.K.); Kyungpook National University, Daegu (S.C.C.); Keimyung University Dongsan Medical Center, Daegu (S.H.H.); Pusan National University Hospital, Busan (T.J.H.); Yeungnam University Hospital, Daegu (Y.J.K.); Chungnam National University Hospital, Daejon (I.W.S.); Chonbuk National University Hospital, Jeonju (J.K.C.); Jeonju Presbyterian Medical Center, Jeonju (J.Y.R.); Seoul National University Bundang Hospital, Seongnam (I.H.C.); Chungbuk National University Hospital, Cheongju (M.C.C.); Konyang University Hospital, Daejon (J.H.B.); Korea University Guro Hospital, Seoul (S.W.R.); Kyunghee University Hospital, Seoul (C.J.K.); Yonsei University Hospital, Seoul (D.C., Y.S.J.); Yonsei University Wonju Christian Hospital, Wonju (J.Y.); Catholic University St. Mary's Hospital, Seoul (W.S.C., K.B.S.); and Asan Medical Center, Seoul (S.J.P.), Korea

Mailing address: Myung Ho Jeong, MD, PhD, FACC, FAHA, FESC, FSCAI, FAPSIC, Principal Investigator of Korea Acute Myocardial Infarction Registry (KAMIR), Professor, The Heart Research Center Designated by Korea Ministry of Health and Welfare, Chonnam National University Hospital, 671 Jaebongro, Dong-gu, Gwangju, 501-757, Republic of Korea. E-mail: myungho@chollian.net

ISSN-1346-9843 doi:10.1253/circj.CJ-11-0263

All rights are reserved to the Japanese Circulation Society. For permissions, please e-mail: cj@j-circ.or.jp 


\begin{tabular}{|c|c|c|c|c|}
\hline & PES ( $n=634)$ & SES ( $n=906)$ & ZES ( $n=228)$ & $P$ value \\
\hline Age (years) & $61.0 \pm 12.1$ & $60.4 \pm 12.7$ & $60.7 \pm 13.0$ & 0.309 \\
\hline Male gender & $432(68.1)$ & $638(70.4)$ & $149(65.4)$ & 0.283 \\
\hline Diabetes mellitus & 218 (34.3) & $275(30.3)$ & $70(30.5)$ & 0.817 \\
\hline Hypertension & $377(59.4)$ & $525(57.9)$ & $124(54.6)$ & 0.452 \\
\hline Dyslipidemia & $52(8.2)$ & $105(11.6)$ & $24(10.7)$ & 0.128 \\
\hline Current smoker & $307(48.5)$ & $419(46.2)$ & $262(46.9)$ & 0.504 \\
\hline Family history of CAD & $37(5.9)$ & $81(8.9)$ & $20(8.6)$ & 0.124 \\
\hline Previous MI & $15(2.4)$ & $17(1.9)$ & $3(1.3)$ & 0.313 \\
\hline Previous $\mathrm{PCl}$ on non-culprit artery & $12(1.9)$ & $34(3.7)$ & $7(3.1)$ & 0.133 \\
\hline Killip class $\geq$ III on presentation & $67(10.6)$ & 99 (10.9) & $23(10.0)$ & 0.896 \\
\hline Systolic BP on presentation & $129.9 \pm 29.9$ & $128.8 \pm 29.7$ & $129.9 \pm 29.6$ & 0.731 \\
\hline Heart rate on presentation & $75.3 \pm 19.6$ & $76.4 \pm 18.7$ & $77.8 \pm 21.4$ & 0.076 \\
\hline LVEF & $52.0 \pm 11.4$ & $51.4 \pm 11.4$ & $51.3 \pm 12.3$ & 0.651 \\
\hline Symptom to balloon time (min) & $271.6 \pm 145.8$ & $271.3 \pm 146.8$ & $279.3 \pm 163.4$ & 0.107 \\
\hline Serum creatinine (mg/dl) & $1.2 \pm 1.3$ & $1.2 \pm 1.7$ & $1.1 \pm 1.1$ & 0.735 \\
\hline \multicolumn{5}{|l|}{ Medications at discharge } \\
\hline Aspirin & 627 (98.9) & $899(99.2)$ & $223(98.0)$ & 0.621 \\
\hline Clopidogrel & $624(98.5)$ & $895(98.8)$ & $226(99.0)$ & 0.667 \\
\hline Cilostazol & $159(25.1)$ & $220(24.3)$ & $48(21.0)$ & 0.162 \\
\hline ACEI & $458(72.3)$ & $635(70.1)$ & $155(68.1)$ & 0.188 \\
\hline ARB & $62(9.8)$ & $91(10.0)$ & $26(11.4)$ & 0.272 \\
\hline$\beta$-blocker & $472(74.5)$ & $689(76.1)$ & $174(76.2)$ & 0.523 \\
\hline Calcium channel blocker & $34(5.4)$ & $68(7.5)$ & $16(7.1)$ & 0.307 \\
\hline Statin & $519(81.9)$ & $753(83.1)$ & $189(82.7)$ & 0.714 \\
\hline
\end{tabular}

Data given as $\mathrm{n}(\%)$ or mean $\pm \mathrm{SD}$.

PES, paclitaxel-eluting stent; SES, sirolimus-eluting stent; ZES, zotarolimus-eluting stent; CAD, coronary artery disease; $\mathrm{MI}$, myocardial infarction; $\mathrm{PCl}$, percutaneous coronary intervention; BP, blood pressure; LVEF, left ventricular ejection fraction; ACEI, angiotensin-converting enzyme inhibitor; ARB, angiotensin II receptor blocker.

cacy. ${ }^{4-6}$ Zotarolimus-eluting stents (ZES) are the newer firstgeneration DES, composed of a new antiproliferative agent and a cobalt-based alloy stent platform integrated with biocompatible phosphorylcholine polymer. ${ }^{7}$ This was expected to be less prone to thrombosis and to have efficacy similar to that of the first-generation DES. Although ZES are increasingly used for the treatment of patients with STEMI, and although randomized comparison with sirolimus-eluting stents (SES) in the ENDEAVOR III trial showed similar clinical outcomes, there have been few direct comparisons of outcomes among the currently approved DES in these patients. ${ }^{7-10}$

Potential differences in safety and efficacy between DESs might be of particular importance when treating high-risk patients. In particular, patients with metabolic syndrome (MS) have been shown to have higher cardiovascular risk, ${ }^{11-13}$ but no data are available on the direct comparison of the clinical outcomes between ZES, SES, and paclitaxel-eluting stents (PES) in these patients complicated with STEMI. The aim of the present study was to compare the clinical outcomes of ZES, SES, and PES as primary PCI in STEMI patients with MS.

\section{Methods}

\section{Subjects}

The Korea Acute Myocardial Infarction Registry (KAMIR) is a prospective, multi-center, observational registry designed to examine current epidemiology, in-hospital management, and outcome of patients with acute myocardial infarction (MI) in Korea for the commemoration of the $50^{\text {th }}$ anniversary of the Korean Circulation Society. ${ }^{14,15}$ The registry consists of 50 community and teaching hospitals with facilities for primary PCI and on-site cardiac surgery. Data were collected by a trained study coordinator using a standardized case report form and protocol. The ethics committee at each participating institution approved the study protocol. Among the 14,072 patients with acute MI between November 2005 and December 2007, 1,768 eligible STEMI patients with MS who underwent primary PCI were sorted according to DES type and followed up during 1 year. Patients were excluded if they had any general contraindication to the revascularization procedure and pharmacologic therapies, had undergone previous PCI or coronary artery bypass graft of the infarct-related artery, or had an estimated life expectancy $<12$ months. These patients were grouped based on the types of DES: a PES group (Taxus, Boston Scientific, Natick, MA, USA), a SES group (Cypher, Cordis, Miami Lakes, FL, USA), and a ZES group (Endeavor, Medtronic Vascular, Santa Rosa, CA, USA). There are no specific criteria for selecting the type of DES.

\section{Study Design}

Patients were enrolled in the registry if they were admitted to participating hospitals with a suspected diagnosis of MI. A diagnosis of MI was made in the presence of serial increases in at least one serum biochemical markers of cardiac necrosis (eg, creatine kinase-myoglobin, troponin I and T), associated with typical electrocardiographic changes and/or typical symptoms suggestive of acute MI. ${ }^{16}$ Patients with ST-segment elevation $\geq 1 \mathrm{~mm}$ in $\geq 2$ extremity electrocardiographic leads or $\geq 2 \mathrm{~mm}$ in $\geq 2$ contiguous precordial leads or new left 


\begin{tabular}{|c|c|c|c|c|}
\hline & PES ( $n=634)$ & SES $(n=906)$ & ZES ( $n=228)$ & $P$ value \\
\hline \multicolumn{5}{|l|}{ Infarction-related artery } \\
\hline Left main stem & $15(2.4)$ & $17(1.9)$ & $4(1.8)$ & 0.582 \\
\hline Left anterior descending & $356(56.1)$ & $516(57.0)$ & $132(58.1)$ & 0.757 \\
\hline Left circumflex & $37(5.8)$ & $81(8.9)$ & $16(6.9)$ & 0.09 \\
\hline Right & $226(35.7)$ & $292(32.2)$ & $76(33.2)$ & 0.241 \\
\hline No. narrowed coronary arteries & & & & 0.06 \\
\hline 1 & $332(52.3)$ & $501(55.3)$ & $118(51.8)$ & \\
\hline 2 & $164(25.8)$ & 207 (22.9) & $73(32.1)$ & \\
\hline 3 & $138(21.9)$ & $198(21.8)$ & $37(16.1)$ & \\
\hline ACC/AHA lesion type & & & & 0.528 \\
\hline$A$ & $10(1.6)$ & $16(1.8)$ & $4(1.9)$ & \\
\hline B1 & $126(19.9)$ & $173(19.1)$ & $51(22.2)$ & \\
\hline B2 & $181(28.5)$ & $264(29.1)$ & $57(24.8)$ & \\
\hline $\mathrm{C}$ & $322(50.8)$ & $453(50.0)$ & $117(51.1)$ & \\
\hline Pre-procedural TIMI flow grade & & & & 0.732 \\
\hline 0 & $371(58.5)$ & $532(58.7)$ & $132(58.1)$ & \\
\hline I & $47(7.4)$ & $99(10.9)$ & $27(11.8)$ & \\
\hline II & $82(13.0)$ & $157(17.3)$ & $37(16.4)$ & \\
\hline III & $132(20.8)$ & $119(13.1)$ & $31(13.7)$ & \\
\hline Post-procedural TIMI flow grade & & & & 0.507 \\
\hline 0 & $10(1.5)$ & $11(1.2)$ & $4(1.6)$ & \\
\hline I & $12(1.9)$ & $24(2.7)$ & $5(2.1)$ & \\
\hline II & $36(5.6)$ & $36(4.0)$ & $11(4.7)$ & \\
\hline III & $577(91.0)$ & $834(92.1)$ & $209(91.6)$ & \\
\hline Stent diameter $(\mathrm{mm})$ & $3.2 \pm 0.4$ & $3.1 \pm 0.4$ & $3.2 \pm 0.5$ & 0.536 \\
\hline Stent length (mm) & $25.2 \pm 6.3$ & $26.2 \pm 6.3$ & $23.8 \pm 5.7$ & 0.004 \\
\hline Stent number per lesion & $1.56 \pm 0.86$ & $1.37 \pm 0.70$ & $1.31 \pm 0.61$ & $<0.001$ \\
\hline Glycoprotein Ilb/IIla inhibitor use & $127(20.1)$ & $179(19.8)$ & $41(17.8)$ & 0.09 \\
\hline
\end{tabular}

Data given as $\mathrm{n}(\%)$ or mean $\pm \mathrm{SD}$.

ACC/AHA, American College of cardiology/American Heart Association; TIMI, Thrombolysis In Myocardial Infarction. Other abbreviations see in Table 1.

\begin{tabular}{|c|c|c|c|c|}
\hline & PES $(n=634)$ & SES $(n=906)$ & ZES (n=228) & $P$ value \\
\hline Major adverse cardiac events ${ }^{\star}$ & $130(20.5)$ & $180(19.9)$ & $43(18.9)$ & 0.239 \\
\hline \multicolumn{5}{|l|}{ In-hospital outcomes } \\
\hline Death & $61(9.6)$ & $98(10.8)$ & $18(8.0)$ & 0.552 \\
\hline Acute or subacute stent thrombosis & $2(0.3)$ & $4(0.4)$ & $1(0.4)$ & 0.773 \\
\hline Major bleeding events & $6(0.9)$ & $11(1.2)$ & $2(0.9)$ & 0.918 \\
\hline \multicolumn{5}{|l|}{ 12-month outcomes (cumulative) } \\
\hline Death & $87(13.7)$ & $132(14.5)$ & $27(11.8)$ & 0.08 \\
\hline MI & $7(1.1)$ & $6(0.7)$ & $3(1.3)$ & 0.558 \\
\hline \multicolumn{5}{|l|}{ Repeated PCI } \\
\hline Target lesion revascularization & $36(5.6)$ & $42(4.6)$ & $13(5.9)$ & 0.118 \\
\hline Target vessel revascularization & $25(3.9)$ & $37(4.1)$ & $8(3.5)$ & 0.593 \\
\hline Coronary artery bypass graft & $7(1.1)$ & $7(0.8)$ & $2(0.9)$ & 0.720 \\
\hline Stent thrombosis (definite/probable) & $6(0.9)$ & $9(1.0)$ & $3(1.3)$ & 0.448 \\
\hline
\end{tabular}

${ }^{*}$ Composite of death, $\mathrm{MI}$, and target lesion revascularization. Abbreviations see in Table 1.

bundle branch block on the admission electrocardiogram were defined as having STEMI. Reperfusion was expected to be achieved within $6 \mathrm{~h}$ after onset of symptoms, and the native coronary artery was considered to be suitable for primary PCI.

All patients received $\geq 100 \mathrm{mg}$ of aspirin and a 300-600-mg loading dose of clopidogrel and unfractionated heparin (50$70 \mathrm{U} / \mathrm{kg}$ ) to maintain an activated clotting time at $>250-300 \mathrm{~s}$ before, or during the procedure. Loading doses of aspirin and clopidogrel were given after patients agreed to undergo PCI. The maintenance dose was $100 \mathrm{mg} /$ day for aspirin and $75 \mathrm{mg} /$ day for clopidogrel. 


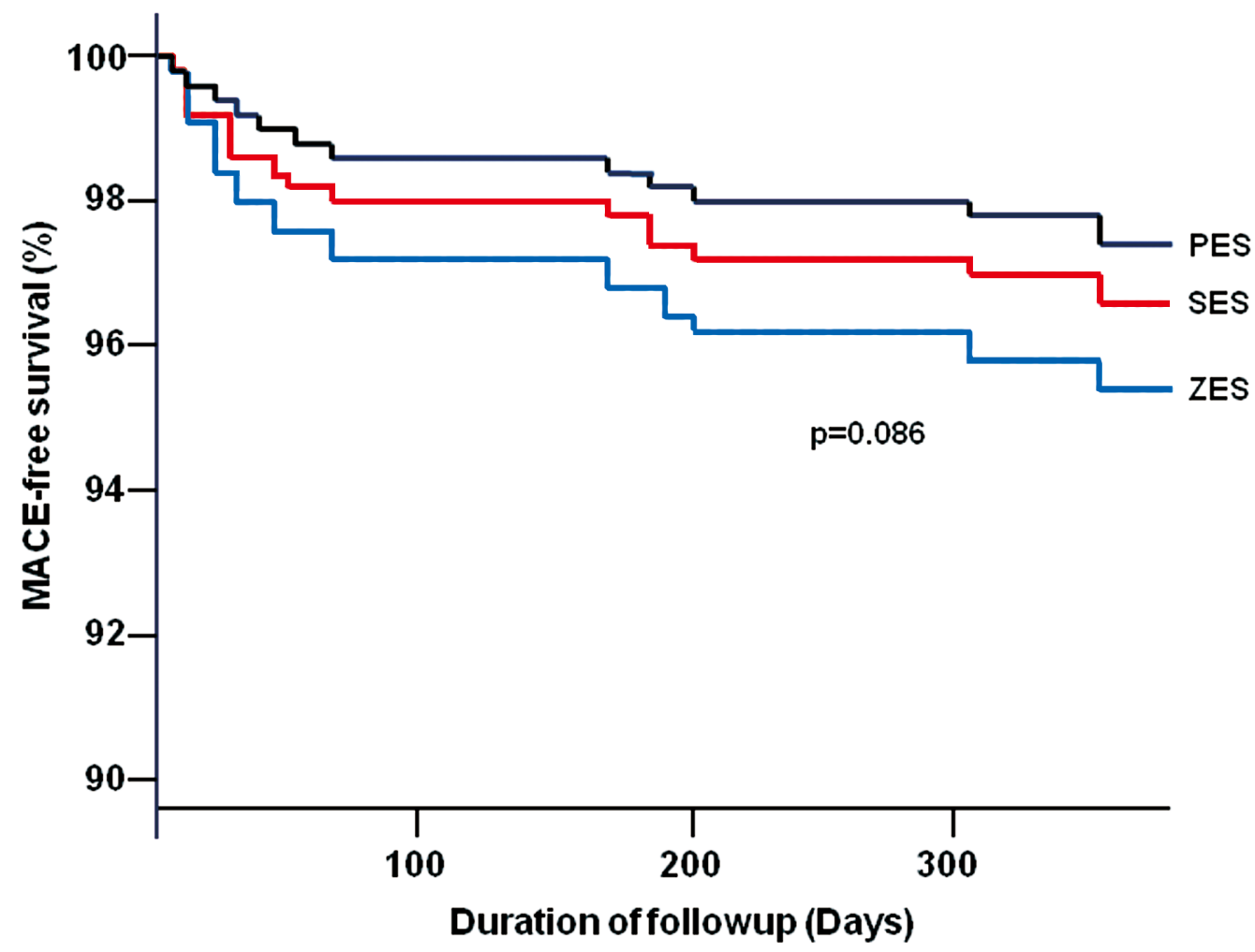

Patients at risk

PES 634

SES 906

ZES 228
591

843

213
565

801

202
511

728

181
278

469

97

Figure 1. Adjusted 12-month major adverse cardiac event (MACE: composite of all-cause death, myocardial infarction, and target lesion revascularization)-free survival in 3 drug-eluting stent groups: paclitaxel-eluting stent (PES), sirolimus-eluting stent (SES) and zotarolimus-eluting stent (ZES). This result did not include in-hospital death.

We analyzed baseline demographic and clinical characteristics and relevant laboratory results. Echocardiography was performed in all patients before discharge. The morphology of lesion in coronary angiography was classified according to the criteria of the American College of Cardiology/American Heart Association (ACC/AHA). ${ }^{17}$ The degree of coronary flow was classified using Thrombolysis In Myocardial Infarction (TIMI) score. ${ }^{18}$

The primary endpoint was major adverse cardiac events (MACE) at the 12-month clinical follow-up and MACE were defined as the composite of (1) all-cause death; (2) recurrent MI; and (3) target lesion revascularization (TLR). Recurrent MI was defined as the recurrence of symptoms or new electrocardiographic changes compatible with MI in association with a rise in cardiac enzymes at least twice the upper limit of normal. TLR was defined as any revascularization of the target lesion due to re-stenosis or reocclusion within $5 \mathrm{~mm}$ proximal or distal to the stent. Secondary endpoint included individual components of the composite primary endpoint and stent thrombosis. Stent thrombosis was defined as definite and probable stent thrombosis according to the Academic Research Consortium definition. ${ }^{19}$ Major bleeding was defined as any intracranial bleeding, bleeding with a hemoglobin decrease of $>5 \mathrm{~g} / \mathrm{dl}$, or hematocrit decrease of $>15 \%$, as judged by the TIMI investigators. All data were recorded on a standardized, electronic, web-based registry at http://www. kamir.or.kr.

\section{Definition of MS}

For the diagnosis of MS at baseline, we used the National Cholesterol Education Program-Adult Treatment Panel (NCEPATP) III criteria. Namely, central obesity was defined as waist circumference $>90 \mathrm{~cm}$ in men or $>80 \mathrm{~cm}$ in women according to the modified ATP III guideline that WHOWestern Pacific Region and International Association for the Study of Obesity presented for Asian populations in 2000. The presence of MS was analyzed considering the presence of the following criteria: (1) central obesity: waist circumference $>90 \mathrm{~cm}$ (men), $>80 \mathrm{~cm}$ (women); (2) fasting triglyceride level $\geq 150 \mathrm{mg} / \mathrm{dl}$; (3) reduced high-density lipoprotein cholesterol: $<40 \mathrm{mg} / \mathrm{dl}$ (men), $<50 \mathrm{mg} / \mathrm{dl}$ (women); (4) hypertension: blood pressure $\geq 130 / 85 \mathrm{mmHg}$ or taking anti-hypertensive medication; and (5) impaired fasting glucose (IFG): fasting glucose $\geq 110 \mathrm{mg} / \mathrm{dl}$ or taking medication or past history of type 2 diabetes mellitus (DM). Patients were considered to have MS in the presence of $\geq 3$ criteria, according to the defi- 


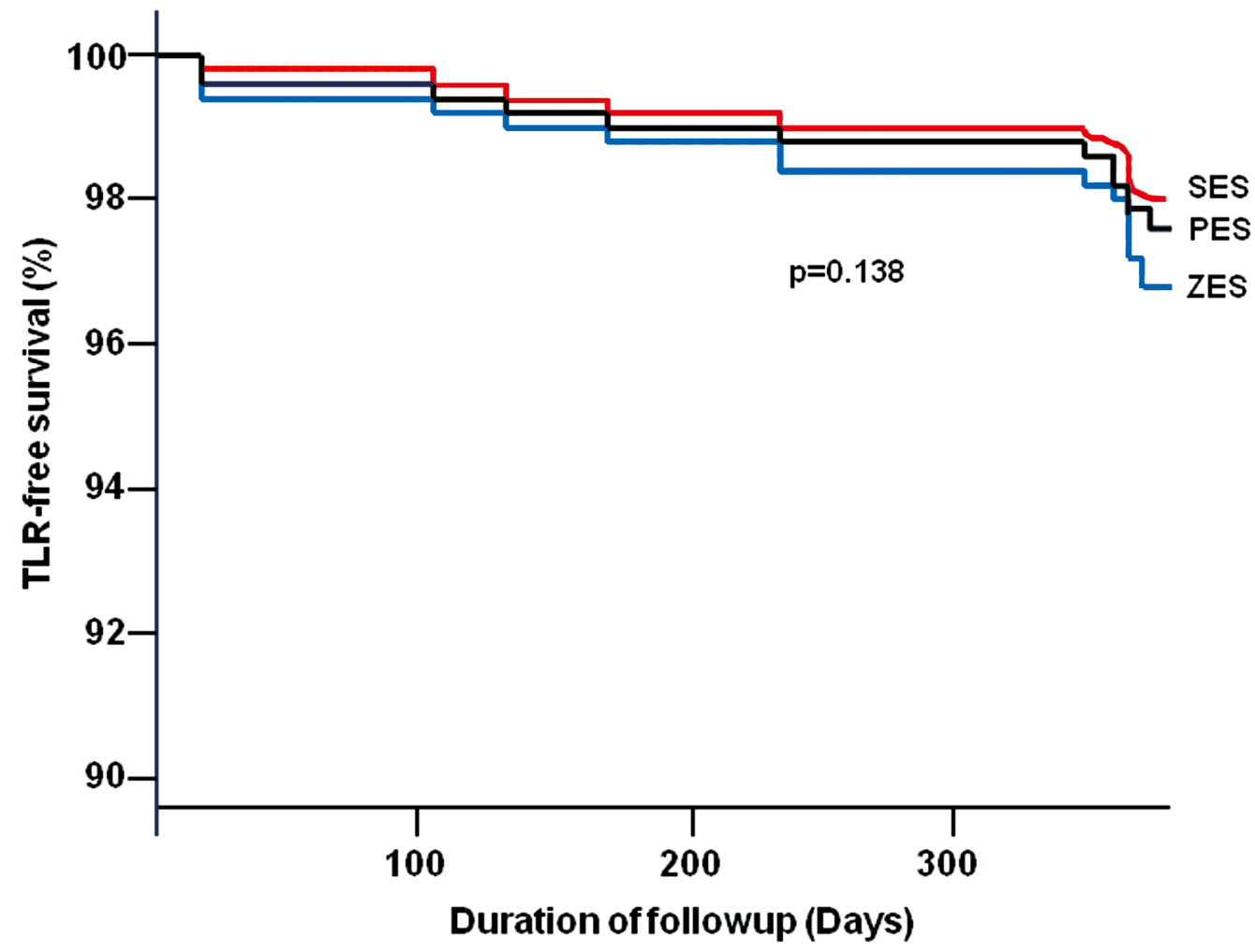

Patients at risk

$\begin{array}{lllllc}\text { PES } & 634 & 591 & 562 & 508 & 271 \\ \text { SES } & 906 & 842 & 798 & 722 & 463 \\ \text { ZES } & 228 & 212 & 219 & 180 & 94\end{array}$

Figure 2. Adjusted 12-month target lesion revascularization (TLR)-free survival in 3 drug-eluting stent groups: paclitaxel-eluting stent (PES), sirolimus-eluting stent (SES), and zotarolimus-eluting stent (ZES). This result did not include in-hospital death.

nition proposed by the American Heart Association/National Heart, Lung, and Blood Institute (AHA/NHLBI). Although the AHA/NHLBI guideline recommended the definition of IFG at or above $100 \mathrm{mg} / \mathrm{dl},{ }^{20}$ the present study adopted the NCEP-ATP III guideline. All patients were reviewed immediately after admission to emergency department, and biological measurements were performed in the fasting state during the hospital stay.

\section{Statistical Analysis}

All analyses were done using SPSS for Windows, version 17.0 (Chicago, IL, USA). Continuous variables are expressed as mean \pm SD and analyzed using ANOVA. Categorical variables are expressed as percentages and were compared using the chi-squared test. All statistical tests were 2-tailed, with statistical significance defined as a $\mathrm{P}<0.05$. Adjusted survival curves were calculated with the use of Cox regression models. In order to adjust confounding factors in Cox regression models, we included variables as covariates that had $\mathrm{P}<0.2$ on univariate analysis for endpoints and other variables that have been reported to be associated with prognosis of patients with acute MI. Included variables were age, male gender, history of hypertension, history of DM, history of dyslipidemia, family history of coronary artery disease, previous MI, current smoker, Killip class on presentation, left ventricular ejection fraction, symptom to balloon time, serum creatinine level, creatine kinase-myoglobin, use of glycoprotein $\mathrm{Ilb} / \mathrm{III}$ inhibitor, left main complex disease as culprit lesion, multivessel disease, lesion complexity, post-procedural TIMI flow, stent diameter, stent length, and discharge medications including aspirin, clopidogrel, cilostazol, $\beta$-blocker, angiotensin-converting enzyme inhibitor, angiotensin II receptor blocker and statin. The results are given as adjusted hazard ratio (HR) with $95 \%$ confidence interval $(95 \% \mathrm{CI})$.

\section{Results}

\section{Baseline Characteristics and Angiographic Findings}

A total of 1,768 patients who presented with acute STEMI for primary PCI were included in the present study. The study group was divided into 3 groups according to DES type (PES group, 634 patients; SES group, 906 patients; ZES group, 228 patients). The baseline clinical characteristics are listed in Table 1 and there were no significant differences between the 3 groups. Dyslipidemia was defined as history of dyslipidemia or taking medication for dyslipidemia, not by laboratory findings during admission. Therefore, the prevalence of dyslipidemia was low. Also, the discharge medications are 


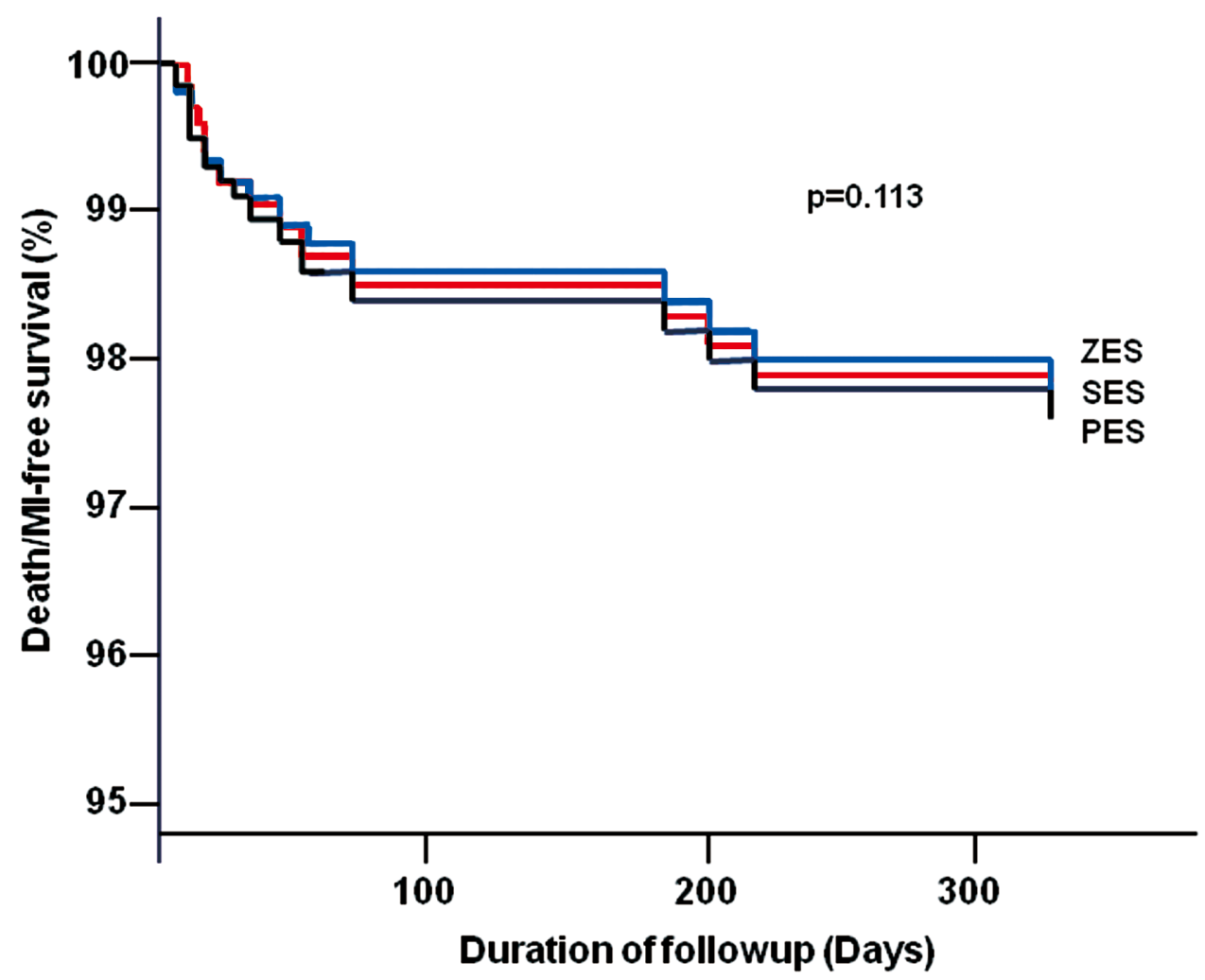

\section{Patients at risk}

PES 634

SES 906

ZES 228
590

841

214
561

795

218
506

723

178
272 465 96

Figure 3. Adjusted 12-month death/myocardial infarction (MI)-free survival in 3 drug-eluting stent groups: paclitaxel-eluting stent (PES), sirolimus-eluting stent (SES), and zotarolimus-eluting stent (ZES). This result did not include in-hospital death.

listed in Table 1. Between the 3 groups, no significant differences were present in the type of medications that can affect the clinical outcome such as antiplatelet agents, $\beta$-blockers, and statins. Table 2 lists the coronary angiographic and procedural characteristics. The location and complexity of the infarct-related artery and post-procedural TIMI flow grade were similar between the 3 groups. Although the ZES group had a lower incidence of 3-vessel disease and a lower tendency of glycoprotein IIb/IIIa inhibitor usage compared with other groups, there were no statistically meaningful differences. The SES group, however, had a longer stent length, and the PES group had more stents implanted than the other groups.

\section{In-Hospital Outcomes and MACE}

The in-hospital mortality rate, incidence of acute stent thrombosis, and incidence of major bleeding events were similar between the 3 groups (Table 3). The rate of follow-up coronary angiography was $41.5 \%$ (263/634) in the PES group, $48.9 \%$ (443/906) in the SES group, and $40.1 \%(91 / 228)$ in the ZES group $(\mathrm{P}=0.511)$. This relatively high rate of followup angiography might be caused by enrollment of high-risk patients, that is, the STEMI patients with MS. Principally, the investigators recommended follow-up angiography for all enrolled patients. Stent thrombosis during admission occurred in 2 patients in the PES group, in 4 patients in the SES group, and in 1 patient in the ZES group $(\mathrm{P}=0.773)$. The cumulative incidence of primary endpoints at the 12 months clinical follow-up examination was not significantly different between the 3 groups $(\mathrm{P}=0.086)$. Adjusted survival curves did not show meaningful differences in incidence of primary endpoint (Figure 1), TLR (Figure 2), and death or recurrent MI (Figure 3). Cumulative stent thrombosis during the follow-up period occurred less often in the PES group, but the difference was not statistically different among the 3 groups $(\mathrm{P}=0.448)$.

\section{Discussion}

In the present study we compared mid-term clinical outcomes after implantation of PES, SES, or ZES for the treatment of STEMI in patients with MS in the large dedicated registry data to date. The major findings of the present study are as follows: (1) there was no difference in the overall rate of MACE at 12 months among the PES, SES, and ZES groups; and (2) the rate of TLR was not meaningfully different among the 3 DES. 
MS is rapidly increasing in frequency. Also, MS is known to be associated with increased risk of death and cardiovascular events in patients with MI. ${ }^{21}$ Considering that MS is frequent in real-world practice, it may be very important to investigate which DES is most effective in treating MS patients. There are very limited data, however, regarding comparisons among DESs in the treatment of STEMI patients with MS. Therefore, we compared the mid-term clinical outcomes after PCI with the 3 most widely available DES: PES, SES, and ZES, using the KAMIR data.

Stent implantation has improved procedural success and long-term outcomes, and reduced clinical and angiographic re-stenosis compared with plain old balloon angioplasty, so it has become the preferred approach for treating STEMI.,22 As compared with BMS, DES decrease angiographic restenosis and the necessity of repeated revascularization by reducing neointimal hyperplasia, so many interventionists are currently using DES for patients with STEMI. Concerns remain, however, over the use of DES in this situation because patients with STEMI are expected to be at higher risk of stent thrombosis. The Global Registry of Acute Coronary Events (GRACE) registry data showed that patients with STEMI who had DES implanted were at higher risk of dying compared to patients who had BMS. ${ }^{23}$ In contrast, 2 large, randomized, controlled trials, Trial to Assess the Use of the Cypher Stent in Acute Myocardial Infarction Treated with Balloon Angioplasty (TYPHOON) and Paclitaxel-Eluting Stent versus Conventional Stent in Myocardial Infarction with ST-Segment Elevation (PASSION), suggested that DES can be used safely in the setting of primary angioplasty and are likely to decrease the need for repeated revascularization. ${ }^{24,25}$ Also, recent meta-analysis and registry data including the Harmonizing Outcomes with Revascularization and Stents in Acute Myocardial Infarction (HORIZONS-AMI) trial showed that the risk of reintervention was significantly lower in those treated with DES compared to BMS, even if the risks of stent thrombosis, death, or recurrent MI were each similar for patients treated with DES and BMS. ${ }^{26-29}$ First-generation DES (Cypher and Taxus) now seem to be superior to BMS in improving 1 year event-free survival in patients with STEMI.

First-generation DES are known to be effective in lowering the risk of re-stenosis compared to BMS. In the setting of STEMI, there were no differences in MACE rates between PES and SES, although angiographic re-stenosis rate at 6 months was lower for SES implantation. A pre-clinical study showed that the ZES, a newer first-generation DES based on a different type of biostable polymer, induced less inflammation compared with past first-generation DES and improved arterial healing. ${ }^{30}$ In the ENDEAVOR III study, increased neointimal hyperplasia and greater angiographic late lumen loss using ZES compared to SES were observed, but the clinical outcomes were not different between the 2 DES groups. ${ }^{9}$ In the present study there were no significant differences in repeat revascularization rate and 1-year mortality among the 3 DES in MS patients within the setting of STEMI. The SORT OUT III study, however, showed that SES is superior to ZES for low-risk patients receiving routine clinical care during an 18-month follow-up. ${ }^{31}$ The discrepancy of the outcomes between the present study and SORT OUT III study might be due to enrolled patient characteristics and the clinical setting. Stent thrombosis is a dramatic clinical event associated with MI and frequent mortality. Although the ZES group was expected to have a lower rate of stent thrombosis compared to earlier first-generation DES, stent thrombosis occurred at a similar rate in the present study and in a ran- domized trial. ${ }^{32}$ Also, another randomized trial in Korea (the ZEST trial: "Comparison of the Efficacy and Safety of Zotarolimus-Eluting Stent versus Sirolimus-Eluting stent and Paclitaxel-Eluting Stent for Coronary Lesions") showed that ZES is significantly less favorable than SES in the rate of stent thrombosis ( $0 \%$ in SES, $0.7 \%$ in ZES, $0.8 \%$ in PES). In the ZEST trial, patients with STEMI and severe left ventricular dysfunction were excluded, and these factors are known to be independent predictors of stent thrombosis. ${ }^{33}$ Therefore the difference in enrolled patient characteristics might be a reason for this disparity.

Even though these 3 DES rely on different mechanisms of action, the clinical outcomes at 12 months in the present large comparison indicate that, in real-world practice, the selection of either PES, SES, or ZES results in almost identical clinical results. All these findings suggest that these 3 DES may be equally safe and effective for MS patients in the setting of STEMI. Hence, the presence of MS may not affect the selection of DES for STEMI patients in the era of primary PCI.

\section{Study Limitations}

The present study had the inherent limitations of any nonrandomized multicenter registry. First, the registry findings can be limited by low rates of enrollment and underreporting of events, so they could have resulted in a selection bias, although they reflect the real world better than controlled randomized studies. Other selection bias might develop because selection of the type of DES was mainly performed at the operator's discretion. Also, it is possible that some potential confounders were included in the analysis. The KAMIR database, however, was relatively large and closely monitored, and included patients treated at hospitals of various sizes and settings, making it more representative of current practice patterns than a single-site database. Second, the number of patients who had undergone PES, SES, and ZES implantation was unequal. Thus, the data might lack precision for uncommon clinical events, including stent thrombosis. In the present trial, however, revascularization and MACE rates were clinically driven and thus were as close to reality as possible. Third, the present registry data did not include adiponectin plasma levels. It is generally considered that adiponectin plasma level is an important factor for MACE in patients with STEMI, and the relationship between waist circumference and adiponectin level was unclear. Therefore the lack of adiponectin plasma level could be a limitation. Finally, 12-month follow-up may be too short for conclusive determination of the long-term safety of DES in the setting of STEMI. A larger and more adequately powered prospective randomized study of a longer duration may be needed to clarify this issue.

\section{Conclusions}

Drug-eluting stent may be safe and effective in primary PCI for STEMI patients with MS, with no significant differences in MACE and stent thrombosis among the 3 DES.

\section{Acknowledgments}

This study was performed with the support of the Korean Society of Circulation in commemoration of the $50^{\text {th }}$ Anniversary of The Korean Society of Circulation and the Korea Healthcare technology R\&D project (A084869), Ministry for Health and Welfare, Korea.

\section{Disclosure}

There are no potential conflicts to declare. 


\section{References}

1. Keeley EC, Boura JA, Grines CL. Primary angioplasty versus intravenous thrombolytic therapy for acute myocardial infarction: A quantitative review of 23 randomised trials. Lancet 2003; 361: 13 20.

2. Zhu MM, Feit A, Chadow H, Alam M, Kwan T, Clark T. Primary stent implantation compared with primary balloon angioplasty for acute myocardial infarction: A meta-analysis of randomized clinical trials. Am J Cardiol 2001; 88: 297-301.

3. Moses JW, Leon MB, Popma JJ, Fitzgerald PJ, Holmes DR, O'Shaughnessy C, et al; the SIRIUS Investigators. Sirolimus-eluting stents versus standard stents in patients with stenosis in a native coronary artery. $N$ Engl J Med 2003; 349: 1315-1323.

4. Windecker S, Remondino A, Eberli FR, Jüni P, Räber L, Wenaweser $\mathrm{P}$, et al. Sirolimus-eluting and paclitaxel-eluting stents for coronary revascularization. $N$ Engl J Med 2005; 353: 653-662.

5. Schömig A, Dibra A, Windecker S, Mehilli J, Suárez de Lezo J, Kaiser C, et al. A meta-analysis of 16 randomized trials of sirolimus-eluting stents versus paclitaxel-eluting stents in patients with coronary artery disease. J Am Coll Cardiol 2007; 50: 1373-1380.

6. Dibra A, Kastrati A, Mehilli J, Pache J, Schühlen H, von Beckerath $\mathrm{N}$, et al; ISAR-DIABETES Study Investigators. Paclitaxel-eluting or sirolimus-eluting stents to prevent restenosis in diabetic patients. N Engl J Med 2005; 353: 663-670.

7. Kandzari DE, Leon MB. Overview of pharmacology and clinical trials program with the zotarolimus-eluting endeavor stents. J Interv Cardiol 2006; 19: 405-413.

8. Gershlick A, Kandzari DE, Leon MB, Wijns W, Meredith IT, Fajadet J, et al; the ENDEAVOR Investigators. Zotarolimus-eluting stents in patients with native coronary artery disease: Clinical and angiographic outcomes in 1,317 patients. Am J Cardiol 2007; 100(Suppl): $45 \mathrm{M}-55 \mathrm{M}$.

9. Kandzari DE, Leon MB, Popma JJ, Fitzgerald PJ, O'Shaughnessy $\mathrm{C}$, Ball MW, et al; the ENDEAVOR III Investigators. Comparison of zotarolimus-eluting and sirolimus-eluting stents in patients with native coronary artery disease: A randomized controlled trial. J Am Coll Cardiol 2006; 48: 2440-2447.

10. Meredith IT, Ormiston J, Whitbourn R, Kay IP, Muller D, Popma JJ, et al; the ENDEAVOR I Investigators. Four-year clinical followup after implantation of the Endeavor zotarolimus-eluting stents: ENDEAVOR I, the first-in-human study. Am J Cardiol 2007; 100 (Suppl 8B): 56M-61M.

11. Marroquin OC, Kip KE, Kelley DE, Johnson BD, Shaw LJ, Bairey Merz CN, et al; the Women's Ischemic Syndrome Evaluation. Metabolic syndrome modifies the cardiovascular risk associated with angiographic coronary artery disease in women: A report from the Women's Ischemic Syndrome Evaluation. Circulation 2004; 109: $714-721$.

12. Klein BE, Klein R, Lee KE. Components of the metabolic syndrome and risk of cardiovascular disease and diabetes in Beaver Dam. Diabetes Care 2002; 25: 1790-1794.

13. Ninomiya JK, L'Italien G, Criqui MH, Whyte JL, Gamst A, Chen RS. Association of the metabolic syndrome with history of myocardial infarction and stroke in the Third National Health and Nutrition Examination Survey. Circulation 2004; 109: 42-46.

14. Chen KY, Rha SW, Li YJ, Poddar KL, Jin Z, Minami Y, et al; Korea Acute Myocardial infarction Registry Investigators. Triple versus dual antiplatelet therapy in patients with acute ST-segment elevation myocardial infarction undergoing primary percutaneous coronary intervention. Circulation 2009; 119: 3207-3214.

15. Sim DS, Jeong MH, Ahn YK, Kim YJ, Chae SC, Hong TJ, et al; Korea Acute Myocardial Infarction Registry Investigators. Safety and benefit of early elective percutaneous coronary intervention after successful thrombolytic therapy for acute myocardial infarction. Am J Cardiol 2009; 103: 1333-1338.

16. French JK, White HD. Clinical implications of the new definition of myocardial infarction. Heart 2004; 90: 99-106.

17. Kini AS. Coronary angiography, lesion classification and severity assessment. Cardiol Clin 2006; 24: 153-162.

18. Maginas A, Gatzov P, Chasikidis C, Voudris V, Pavlides G, Cokkinos DV. Estimation of coronary flow reserve using the Thrombolysis In Myocardial Infarction (TIMI) frame count method. Am J Cardiol 1999; 83: $1562-1565$.

19. Cutlip DE, Windecker S, Mehran R, Boam A, Cohen DJ, van Es GA, et al; Academic Research Consortium. Clinical end points in coronary stent trials: A case for standardized definitions. Circulation 2007; 115: 2344-2351.

20. Grundy SM, Cleeman JI, Daniels SR, Donato KA, Eckel RH,
Franklin BA, et al. Diagnosis and management of the metabolic syndrome: An American Heart Association/National Heart, Lung, and Blood Institute scientific statement. Circulation 2005; 112: 2735 2752.

21. Levantesi G, Macchia A, Marfisi R, Franzosi MG, Maggioni AP, Nicolosi GL, et al; the GISSI-Prevenzione Investigators. Metabolic syndrome and risk of cardiovascular events after myocardial infarction. J Am Coll Cardiol 2005; 46: 277-283.

22. Fischman DL, Leon MB, Baim DS, Schatz RA, Savage MP, Penn I, et al; the Stent Restenosis Study Investigators. A randomized comparison of coronary-stent placement and balloon angioplasty in the treatment of coronary artery disease: Stent Restenosis Study Investigators. N Engl J Med 1994; 331: 496-501.

23. Steg G. DES fall from GRACE in STEMI: Patients face more than fourfold higher risk of death than bare-metal stent treated patients. Heart-wire. http://www.medscape.com (accessed 29 January, 2008).

24. Laarman GJ, Suttorp MJ, Dirksen MT, van Heerebeek L, Kiemeneij F, Slagboom T, et al. Paclitaxel-eluting versus uncoated stents in primary percutaneous coronary intervention. N Engl J Med 2006; 355: $1105-1113$.

25. Spaulding C, Henry P, Teiger E, Beatt K, Bramucci E, Carrié D, et al; the TYPHOON Investigators. Sirolimus-eluting versus uncoated stents in acute myocardial infarction. $N$ Engl J Med 2006; 355: 1093-1104.

26. Kastrati A, Dibra A, Spaulding C, Laarman GJ, Menichelli M, Valgimigli $\mathrm{M}$, et al. Meta-analysis of randomized trials on drugeluting stents versus bare-metal stents in patients with acute myocardial infarction. Eur Heart J 2007; 28: 2706-2713.

27. Nakagawa Y. What is the effectiveness of drug-eluting stents in the treatment of ST-elevation myocardial infarction?: Should drug-eluting stents be indicated for patients with acute coronary syndrome? (Pro) Circ J 2010; 74: 2225-2231.

28. Stone GW, Lansky AJ, Pocock SJ, Gersh BJ, Dangas G, Wong SC, et al; the HORIZONS-AMI Trial Investigators. Paclitaxel-eluting stents versus bare-metal stents in acute myocardial infarction. N Engl J Med 2009; 360: 1946-1959.

29. Park KW, Kang SH, Chung WY, Lee HY, Park JS, Kang HJ, et al. 'Real world' comparison of drug-eluting stents vs bare metal stents in the treatment of unselected patients with acute ST-segment elevation myocardial infarction. Circ J 2010; 74: 1111-1120.

30. Nakazawa G, Finn AV, John MC, Kolodgie FD, Virmani R. The significance of preclinical evaluation of sirolimus-, paclitaxel-, and zotarolimus-eluting stents. Am J Cardiol 2007; 100(Suppl): 36M44M.

31. Rasmussen K, Maeng M, Kaltoft A, Thayssen P, Kelbæk H, Tilsted $\mathrm{HH}$, et al; the SORT OUT III study group. Efficacy and safety of zotarolimus-eluting and sirolimus-eluting coronary stents in routine clinical care (SORT OUT III): A randomized controlled superiority trial. Lancet 2010; 375: 1090-1099.

32. Chevalier B, Di Mario C, Neumann FJ, Ribichini F, Urban P, Popma JJ, et al; ZoMaxx I investigators. A randomized, controlled, multicenter trial to evaluate the safety and efficacy of zotarolimusversus paclitaxel-eluting stents in de novo occlusive lesions in coronary arteries: The ZoMaxx I trial. J Am Coll Cardiol Interv 2008; 1: 524-532.

33. Buonamici P, Marcucci R, Migliorini A, Gensini GF, Santini A, Paniccia R, et al. Impact of platelet reactivity after clopidogrel administration on drug-eluting stent thrombosis. J Am Coll Cardiol 2007; 49: 2312-2317.

\section{Appendix}

Korea Acute Myocardial Infarction Registry Investigators

Myung Ho Jeong, MD; Young Jo Kim, MD; Chong Jin Kim, MD; Myeong Chan Cho, MD; Youngkeun Ahn, MD; Jong Hyun Kim, MD; Shung Chull Chae, MD; Seung Ho Hur, MD; In Whan Seong, MD; Taek Jong Hong, MD; Dong Hoon Choi, MD; Jei Keon Chae, MD; Jae Young Rhew, MD; Doo Il Kim, MD; In Ho Chae, MD; Jung Han Yoon, MD; Bon Kwon Koo, MD; Byung Ok Kim, MD; Myoung Yong Lee, MD; Kee Sik Kim, MD; Jin Yong Hwang, MD; Seok Kyu Oh, MD; Nae Hee Lee, MD; Kyoung Tae Jeong, MD; Seung Jea Tahk, MD; Jang Ho Bae, MD; Seung Woon Rha, MD; Keum Soo Park, MD; Kyoo Rok Han, MD; Tae Hoon Ahn, MD; Moo Hyun Kim, MD; Ju Young Yang, MD; Chong Yun Rhim, MD; Hyeon Cheol Gwon, MD; Seong Wook Park, MD; Young Youp Koh, MD; Seung Jae Joo, MD; Soo Joong Kim, MD; Dong Kyu Jin, MD; Jin Man Cho, MD; Jeong Gwan Cho, MD; Wook Sung Chung, MD; Yang Soo Jang, MD; Ki Bae Seung, MD; and Seung Jung Park, MD. 